\title{
Impact of high-risk fertility behaviours on underfive mortality in Asia and Africa: evidence from Demographic and Health Surveys
}

Rafi Amir-ud-Din ${ }^{1}$ (D), Lubna Naz ${ }^{2}$, Aneela Rubi ${ }^{3}$, Muhammad Usman ${ }^{4}$ and Umesh Ghimire ${ }^{5^{*}}$ (D)

\begin{abstract}
Background: Maternal age $<18$ or $>34$ years, short inter-pregnancy birth interval, and higher birth order are considered to be high-risk fertility behaviours (HRFB). Underfive mortality being disproportionately concentrated in Asia and Africa, this study analyses the association between HRFB and underfive mortality in selected Asian and African countries.
\end{abstract}

Methods: This study used Integrated Public Microdata Series-Demographic and Health Surveys (IPUMS-DHS) data from 32 countries in sub-Saharan Africa, Middle East, North Africa and South Asia from 1986 to $2017(N=1,467,728)$. Previous evidence hints at four markers of HRFB: women's age at birth of index child $<18$ or $>34$ years, preceding birth interval $<24$ months and child's birth order $>3$. Using logistic regression, we analysed change in the odds of underfive mortality as a result of i) exposure to HRFB individually, ii) exposure to any single HRFB risk factor, iii) exposure to multiple HRFB risk factors, and iv) exposure to specific combinations of HRFB risk factors.

Results: Mother's age at birth of index child $<18$ years and preceding birth interval (PBI) $<24$ months were significant risk factors of underfive mortality, while a child's birth order $>3$ was a protective factor. Presence of any single HRFB was associated with $7 \%$ higher risk of underfive mortality $(\mathrm{OR} 1.07 ; 95 \% \mathrm{Cl} 1.04-1.09)$. Presence of multiple HRFBs was associated with 39\% higher risk of underfive mortality (OR 1.39; 95\% Cl 1.36-1.43). Some specific combinations of HRFB such as maternal age $<18$ years and preceding birth interval $<24$ month significantly increased the odds of underfive mortality (OR 2.07; 95\% Cl 1.88-2.28).

Conclusion: Maternal age $<18$ years and short preceding birth interval significantly increase the risk of underfive mortality. This highlights the need for an effective legislation to curb child marriages and increased public investment in reproductive healthcare with a focus on higher contraceptive use for optimal birth spacing.

Keywords: Underfive mortality, High-risk fertility behaviours, women's age at childbirth, Birth spacing and birth order, Demographic and health survey

\footnotetext{
* Correspondence: creationumesh@gmail.com

${ }^{5}$ New ERA, Kalopul, Rudramati Marga, Kathmandu 44600, Bagmati, Nepal

Full list of author information is available at the end of the article
}

(c) The Author(s). 2021 Open Access This article is licensed under a Creative Commons Attribution 4.0 International License, which permits use, sharing, adaptation, distribution and reproduction in any medium or format, as long as you give appropriate credit to the original author(s) and the source, provide a link to the Creative Commons licence, and indicate if changes were made. The images or other third party material in this article are included in the article's Creative Commons licence, unless indicated otherwise in a credit line to the material. If material is not included in the article's Creative Commons licence and your intended use is not permitted by statutory regulation or exceeds the permitted use, you will need to obtain permission directly from the copyright holder. To view a copy of this licence, visit http://creativecommons.org/licenses/by/4.0/. The Creative Commons Public Domain Dedication waiver (http://creativecommons.org/publicdomain/zero/1.0/) applies to the data made available in this article, unless otherwise stated in a credit line to the data. 


\section{Background}

Child mortality is a serious global health issue. Although underfive mortality decreased by $59 \%$ from 93 deaths per 1000 live births in 1990 to 39 in 2018, 5.3 million children died before their fifth birthday in 2018 [1]. SubSaharan Africa (sSA) has the highest mortality rate in the world and contributes $52 \%$ of all underfive deaths, followed by Central and Southern Asia, accounting for $29 \%$ of underfive mortality [2]. Sustainable Development Goal 3 seeks to reduce neonatal mortality to 12 per 1000 live births and underfive mortality to 25 per 1000 live births [3].

Several socioeconomic factors, including mother's age and hereditary characteristics, nutritional status and substance use, were associated with increased child mortality [4]. Lack of skilled human resources, inadequate infrastructure and low investment in health systems have significantly increased the rate of child and maternal mortality in low and middle-income countries (LMICs) $[5,6]$. Among various risk factors of underfive mortality, women's age at the time of birth, interpregnancy interval and child's birth order have particularly been highlighted as some of the most critical risk factors behind underfive mortality [7-9].

Recently, there has been a growing realisation that a woman may simultaneously experience multiple risk factors of underfive mortality, also called high-risk fertility behaviours (HRFB). HRFB can be expressed in terms of women's age at birth being too early or too late, shorter birth intervals and higher numbers of live births [10, 11]. Evidence suggests that HRFB is widespread and a significant cause of neonatal and underfive mortality in LMICs $[12,13]$. Bangladesh Demographic and Health Survey (DHS) showed that $41.8 \%$ of women showed HRFB, out of whom $33 \%$ showing any single HRFB and $8.8 \%$ multiple HRFB [11]. A study from Ethiopia indicated a higher underfive mortality was associated with maternal age 15 to 18 years and having repeated pregnancies with shorter interpregnancy spacing [14].

LMICs face severe socioeconomic and demographic challenges. They also face issues inextricably linked with underfive mortality such as child marriage, high fertility and high population growth. Around $46 \%$ of women in South Asia and $37 \%$ in sSA were married before their $18^{\text {th }}$ birthday [15]. Teenage pregnancy rate in Bangladesh is as high as 35\% [16]. According to 2018 estimates, global fertility rate in Bangladesh was 2.5 and 4.7 in sSA [17]. Global annual population growth rate in 2019 was $1 \%$ as compared with $2.7 \%$ in sSA [18].

Given multiple risk factors of underfive mortality interacting with each other in a complicated way in LMICs, this study sought to analyze links between HRFB and underfive mortality using a large sample of 32 countries in sSA, Middle East, North Africa and South Asia in the period of over three and half decades. Analysis of specific combinations of various HRFBs may highlight structural drivers and inform evidence-based policy for targeted actions against underfive mortality.

\section{Methods \\ Data sources}

We used data from the Integrated Public Use Microdata Series project of Demographic and Health Surveys (IPUMS-DHS) for this study [19]. DHS collects information on critical demographic and health-related indicators such as mortality rates, fertility and family planning using a stratified sample of households based on cluster design with an average response rate of more than $90 \%$. Advantages of using IPUMS-DHS data are that all variables are consistently coded across all countries and survey periods. IPUMS-DHS databases include data about the individual respondents and household information is linked from household recodes. IPUMS-DHS database has data for 35 countries from sSA, Middle East, North Africa and South Asia from1986 to 2017.

We restricted our sample to only those countries with available information about underfive mortality and HRFB in at least one survey wave. According to this criterion, 32 countries from sSA, Middle East, North Africa and South Asia from1986 to 2017 were selected. Sample size was 1,467,728 from 142 survey waves with as little as one survey from Angola and ten from Senegal.

\section{Study outcomes}

Outcome variable is underfive mortality which refers to death of all children under the age of five. Underfive mortality in this study is coded as binary variable: index children who died before reaching the fifth birthday were coded as 1 and those who were alive at the time of the mother's interview and had not yet reached the age of five were coded as 0 .

\section{Exposures}

Exposure variables are HRFBs of the mother, measured by four parameters: mother's age $<18$ at birth of the index child; mother's age $>34$ at birth of the index child; birth interval $<24$ months after the preceding birth up to index birth; and birth order of index child $>3$.

In addition to the four indicators of HRFB individually, we constructed dichotomous variables i.e., any single high-risk fertility behaviour, which took the value 1 if any single risk factor (mother's age at birth $<18$ or $>34$ years or $\mathrm{PBI}<24$ months or birth order $>3$ ) was present, and 0 otherwise. Our next variable of interest was a multicategory variable multiple high-risk fertility behaviour where the absence of any high-risk fertility behaviour (coded as 0) was compared with the presence of any 
single high-risk fertility behaviour (coded as 1) and multiple high-risk fertility behaviours (coded as 2).

Following the literature [10], we also tested seven specific combinations of HRFB: i) mother's age at birth < 18 years and birth interval $<24$ months; ii) mother's age at birth $<18$ years and birth order $>3$; iii) mother's age at birth $<18$ years and birth interval $<24$ months and birth order $>3$; iv) mother's age at birth $>34$ years and birth interval $<24$ months; v) mother's age at birth $>34$ years and birth order $>3$; vi) mother's age at birth $>34$ years and birth interval $<24$ months and birth order $>3$; and vii) birth interval $<24$ months and birth order $>3$.

\section{Potential confounders}

Though many studies have identified a wide array of risk factors of underfive mortality such as size of child at birth [20] and women empowerment [21], antenatal care attendance [22], our criterion for including confounding variables was that they should be associated with both HRFB and underfive mortality. As only those confounding factors can be appropriate for this study which occurred before HRFB and by implication before birth of the index child, size of child at birth, antenatal care attendance and women's empowerment are, therefore, not included in the list of confounding factors.

Recently, a vast literature has emerged, linking breastfeeding with underfive mortality [23]. However, in the context of DHS data, a child could be reported as "never breastfed", because it died young (especially in case of neonatal death). With regard to women's empowerment, this, strictly speaking, is not a binary outcome because it keeps on changing and is a function of several factors which include the birth of her children [24]. Domestic violence against infertile women [25] is just one example how children affect women's life circumstances. As the birth of a child may influence women's life circumstances (for example, birth of male children increases mother's bargaining power within the household especially in some parts of South Asia), mother's empowerment may suffer from endogeneity, and has thus been excluded from the list of potential confounders.

Given the preceding debate on confounding, we have adjusted our model with father's and mother's education, father's and mother's occupation, urban/rural residential status, household wealth status and country and time fixed effects. Parental education variables were constructed with no education as reference and primary, secondary and higher education as the alternative categories. Parental occupation variables were dichotomous, with "not currently working" as reference and "currently working" as alternative. Residential status is also a dichotomous variable with rural residence as reference and urban residence as alternative. Household wealth status is a quintiles index variable with the poorest quintile as reference and poorer, middle, richer and richest quintiles as the alternative categories. We adjusted the models with time fixed effects by categorising the survey years from 1986 to 2017 into three periods: 1986-2000, 2001-2010 and 2011-2017.

\section{Statistical analysis}

We used the logistic regression model to estimate the association between HRFB and underfive mortality. We analysed how exposure to HRFB affects the odds of underfive mortality in four different ways: i) exposure to HRFB individually, ii) exposure to any single HRFB risk factor; iii) exposure to multiple HRFB risk factors; and iv) exposure to specific combinations of HRFB risk factors.

Additionally, we did sub-group country-level analysis by estimating the impact of i) mother's age at birth of the index child $<18$ or $>34$ years, ii) mother's age at birth of the index child $<18$ and $>34$ years separately, iii) preceding birth interval (PBI) $<24$ months and iv) birth order of index child $>3$ on underfive mortality (Figs. 2, 3, 4 and 5). We regressed these variables on underfive mortality using logistic regression for each country separately and estimated adjusted odds ratios of these variables. Each model was adjusted for father's and mother's education, father's and mother's occupation, urban/rural residential status, household wealth status and country and time fixed effects. We used Stata's command idpover to make forest plots for each country in the sample. Odds ratios of all countries were averaged to give the overall effect of different measures of HFRB on underfive mortality.

Since DHS has a complex survey design, sampling weights are required to correct for the bias in probability selection [26]. Regression analysis was, therefore, done after adjusting for sampling design (stratification and clustering) using "svy" command in Stata/MP 15.1.

\section{Eligibility criteria}

Women aged $15-49$ years who gave birth in the 5 years preceding the interview were included in this analysis. Only singleton births were included because twins have different mortality risks for both children and mother $[27,28]$. The sample includes all singletons born to a woman because restricting the sample to only last born of the singleton birth children would give mortality rates that are significantly different from WHO underfive mortality rates [29].

\section{Results}

Underfive mortality rates revealed significant geographical and temporal differences over the number of surveys in each country (Fig. 1). Average underfive mortality in 32 countries from 1986 to 2017 was 77 per 1000 live 


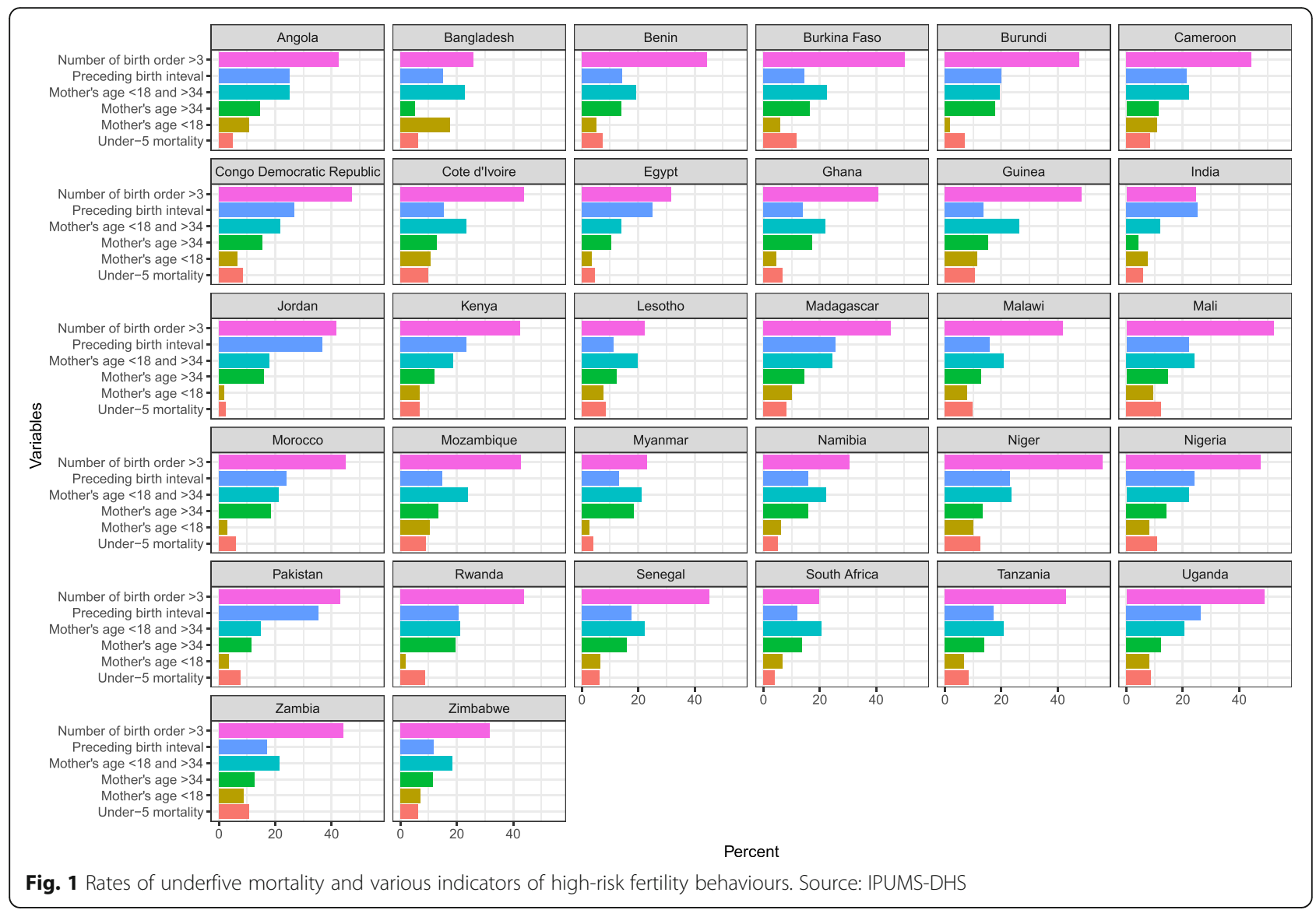

births. Underfive mortality rates in our sample were 93 per 1000 live births during 1986-2000, 77 during 20012010 and 52 during 2011-2017. Jordan had the lowest underfive mortality rate with 22 per 1000 live births and Niger the highest with 125 per 1000 live births. Approximately $7 \%$ of women gave birth before they reached their 18th birthday with the highest percentage concentrated in Bangladesh (17.5\%) and the smallest in Burundi (1.7\%). Approximately $14 \%$ of women gave birth when they were above 34, with the highest percentage in Rwanda (19.4\%) and the smallest in India (4.4\%). Around $21 \%$ of the women $<18$ years or $>34$ years gave birth, with the highest rate in Guinea (26.4\%) and the lowest in India (12\%). Around $20 \%$ of children had a preceding birth interval < 24 months, with the highest in Jordan (36.6\%) and the lowest in Lesotho (11.2\%). Over $40 \%$ of the children had birth order $>3$. The lowest percentage of such children was in India (25\%) and the highest in South Africa (56\%).

\section{Individual high-risk fertility behaviours}

Compared to the reference category of mothers whose age at birth of the index child was $\geq 18$ years, mothers who were $<18$ years had higher odds of underfive mortality (aOR 1.61; 95\% CI 1.56-1.67), unlike women $>34$ years at birth of the index child as compared to mothers aged $\leq 34$ (aOR 0.98; 95\% CI 0.96-1.01; Table 1). Compared to the reference category of women with PBI $\geq 24$ months, those with PBI $<24$ months had higher odds of underfive mortality (aOR 2.02; 95\% CI 1.97-2.07; Table 1). Compared with children with birth order $\leq 3$, children with birth order $>3$ had lower odds of underfive mortality (aOR 0.91; 95\% CI 0.89-0.93; Table 1 ).

\section{Any single high-risk fertility behaviours}

With regards to the reference category of women without HRFB, any single HRFB (mother's age $<18$ or $>34$ or PBI $<24$ months or birth order $>3$ ) was associated with higher odds of underfive mortality (aOR 1.07; 95\% CI 1.04-1.09; Table 2). Increased education of both father and mother, as well as increased household wealth status were significantly associated with lower odds of underfive mortality. In contrast, maternal occupation was associated with higher odds (aOR 1.07; 95\% CI 1.04-1.10), but father's occupation status as well as residential status of the child had no significant impact on the odds of underfive mortality.

\section{Multiple high-risk fertility behaviours}

Compared with women who did not show any risky fertility behaviour, both women with single HRFB (aOR 
Table 1 High-risk fertility behaviours: individual risk factors

\begin{tabular}{ll}
\hline & $(1)$ \\
& $\mathrm{aOR}^{\mathbf{a}}$ \\
\hline Mother's age at birth & \\
$\geq 18$ years & 1 \\
$<18$ years & $1.61^{* * *}$ \\
& $(1.56,1.67)$
\end{tabular}

\section{Mother's age at birth}

$\leq 34$ years

$>34$ years

(2)

aOR

(3)

aOR

(4)

aOR

$(1.56,1.67)$

0.98

$(0.96,1.01)$

\section{Length of $\mathrm{PBI}$}

$\geq 24$ months

$<24$ months

1

$2.02^{* * *}$

$(1.97,2.07)$

\section{Child's birth order number}

First, second, or third born

$>3$

$0.91^{* * *}$

$(0.89,0.93)$

\section{Mother's education}

No Education

Primary

Secondary

Higher

\section{Father's education}

No Education
Primary

Secondary

Higher

\section{Mother's working status}

$$
\begin{aligned}
& \text { Currently not working } \\
& \text { Working }
\end{aligned}
$$

\section{Father's working status}

Currently not working

Working

\section{Residential status}

Rural

Urban
1

$0.92^{* * *}$

$(0.89,0.94)$

$0.74^{* * *}$

$(0.71,0.77)$

$0.56^{* * *}$

$(0.51,0.62)$

1

$0.94^{* * *}$

$(0.91,0.96)$

$0.86^{* * *}$

$(0.83,0.89)$

$0.75^{* * *}$

$(0.70,0.80)$

1

$1.09^{* * *}$

$(1.06,1.12)$

1

0.98

$(0.89,1.07)$

1

$0.96^{* *}$
$0.92^{* * *}$

$(0.90,0.95)$

$0.74^{* * *}$

$(0.71,0.77)$

$0.55^{* * *}$

$(0.50,0.61)$

\section{1}

$0.93^{* * *}$

$(0.91,0.96)$

$0.86^{* * *}$

$(0.83,0.89)$

$0.74^{* * *}$

$(0.70,0.79)$

\section{1}

$1.07^{* * *}$

$(1.05,1.10)$

\section{1}

0.97

$(0.88,1.06)$
1

$0.91^{* * * *}$

$(0.88,0.94)$

$0.73^{* * * *}$

$(0.69,0.76)$

$0.55^{* * *}$

$(0.48,0.63)$

1

$0.90^{* * *}$

$(0.87,0.93)$

$0.85^{* * *}$

$(0.82,0.89)$

$0.78^{* * *}$

$(0.72,0.84)$

1

$1.13^{* * *}$

$(1.09,1.16)$

1

1.00

$(0.89,1.11)$

0.97

$(0.88,1.06)$

1

$0.95^{* *}$
$0.91^{* * *}$

$(0.89,0.94)$

$0.73^{* * *}$

$(0.70,0.76)$

$0.53^{* * *}$

$(0.48,0.58)$

1

$0.92^{* * *}$

$(0.89,0.95)$

$0.85^{* * *}$

$(0.82,0.88)$

$0.74^{* * *}$

$(0.69,0.79)$

$1.09^{* * *}$

$(1.06,1.11)$
$0.94^{* * *}$ 
Table 1 High-risk fertility behaviours: individual risk factors (Continued)

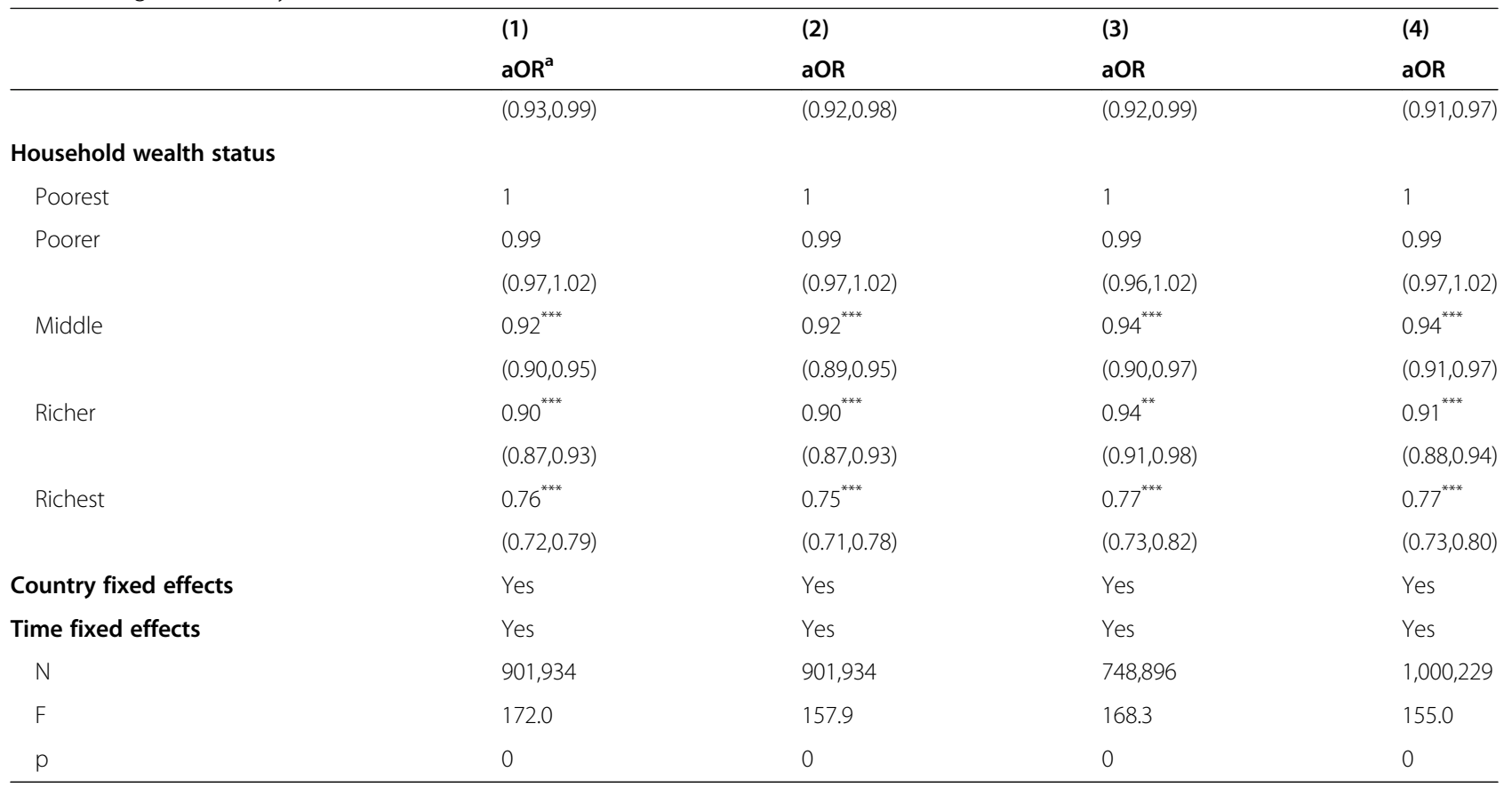

Exponentiated coefficients; $95 \%$ confidence intervals in brackets

${ }^{*} P<0.05,{ }^{* *} P<0.01,{ }^{* * *} P<0.001$

${ }^{\text {a Adjusted odds ratio }}$

1.07; 95\% CI 1.05-1.09) as those with multiple HRFB were associated with higher odds of underfive mortality (aOR 1.39; 95\% CI 1.36-1.43). See further details in Additional File 1.

\section{Specific combinations of risks of high-risk fertility behaviours}

Mother's age $<18$ years at birth of the index child and $\mathrm{PBI}<24$ months were both associated with higher odds of underfive mortality (aOR 2.07; 95\% CI 1.88-2.28; Table 3). The same applied to mother's age $<18$ years at birth of the index child, PBI $<24$ months and birth order $>3$ (aOR 1.997; 95\% CI 1.10-3.62).

Mother's age $>34$ years at birth of the index child and $\mathrm{PBI}<24$ months were also associated with higher risks of underfive mortality (aOR 1.93; 95\% CI 1.89-2.05). PBI $<24$ months and birth order $>3$ were also associated with higher risks of underfive mortality (aOR 1.82; 95\% CI 1.77-1.88). Though mother's age $>34$ years at birth and birth order $>3$ had no significant impact, mother's age $>34$ years at birth of index child, birth order $>3$ and PBI $<24$ months were associated with higher risks of underfive mortality (aOR 1.95; 95\% CI 1.84-2.07). This suggests that PBI $<24$ months was the most important risk factor of underfive mortality.

Out of 32 countries, a statistically significant positive association existed between mother's age $<18$ or $>34$ years at birth of the index child and underfive mortality in 19 countries only (Fig. 2). Overall, odds of underfive mortality were higher for mothers whose age was $<18$ or $>34$ years as compared to mothers aged 18 to 34 years (aOR 1.24; 95\% CI 1.21-1.27). The highest risk of underfive mortality was observed in Egypt (aOR 1.53; 95\% CI 1.34-1.75) and smallest in Zambia (aOR 1.16; 95\% CI 1.03-1.30).

Figure 3 gives country-level ORs of underfive mortality regressed separately on mother's age $<18$ and $>34$ years at birth of index child. In 23 out of 32 countries, maternal age $<18$ years was associated with significantly higher odds of underfive mortality compared to women aged $\geq 18$. Maternal age $>34$ years, however, was a significant risk factor of underfive mortality in only three countries, while it statistically significant protected against underfive mortality in six countries.

In 31 of the 32 countries, PBI < 24 months significantly increased the risk of underfive mortality (Fig. 4). Overall, odds of underfive mortality were higher for children with $\mathrm{PBI}<24$ months as compared to $\mathrm{PBI} \geq 24$ (aOR 1.98; 95\% CI 1.93-2.03). The highest risk with $\mathrm{PBI}<24$ months was observed in Mozambique (aOR 2.75; 95\% CI 2.33-3.24) and the lowest in Jordan (aOR 1.50; 95\% CI 1.24-1.82).

Birth order $>3$ significantly decreased the risk of underfive mortality in 11 countries with only increased risks in two (Fig. 5). No significant association between birth order $>3$ and underfive mortality was found in 19 countries. Overall, odds of underfive mortality were lower for children whose birth order was $>3$ (aOR 0.94; 
Table 2 High-risk fertility behaviours: no HFRB versus any single risk factor

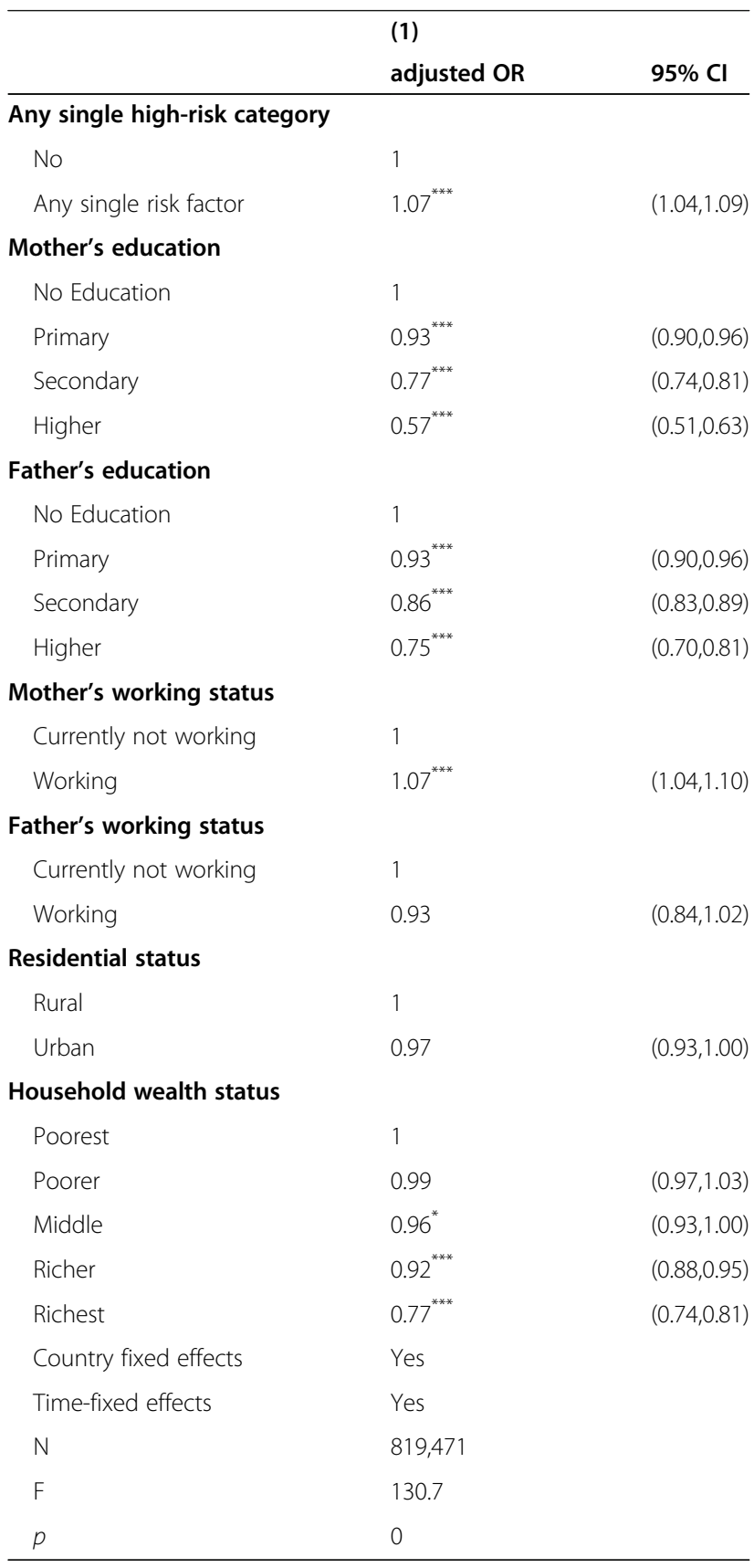

Exponentiated coefficients; $95 \%$ confidence intervals in brackets

${ }^{*} P<0.05,{ }^{* *} P<0.01,{ }^{* * *} P<0.001$

95\% CI 0.92-0.96) with the lowest risk in Zambia (aOR 0.70; 95\% CI 0.64-0.76) and the highest in Myanmar (aOR 1.74; 95\% CI 1.05-2.86).

\section{Discussion}

Underfive mortality rates revealed significant geographical and temporal differences. Average underfive mortality from 32 countries was 77 per 1.000 live births from 1986 to 2017, from a lowest rate in Jordan (22 per 1.000
Table 3 High-risk fertility behaviours: specific combinations of risk factors

\begin{tabular}{ll}
\hline & $\begin{array}{c}\text { (1) } \\
\text { adjusted OR }\end{array}$ \\
\hline $\begin{array}{l}\text { Age at birth }<18 \text { years and birth interval }<24 \text { months } \\
\text { No }\end{array}$ & 1 \\
Yes & $2.07^{* * *}$ \\
& $(1.88,2.28)$ \\
Age at birth $<18$ years and birth order $>3$ & \\
No & 1 \\
Yes & $1.82^{*}$ \\
& $(1.11,3.01)$
\end{tabular}

Age at birth $<18$ years and birth interval $<24$ months and birth order $>3$

$\begin{array}{ll}\text { No } & 1 \\ \text { Yes } & 2.00^{*}\end{array}$

$(1.10,3.62)$

Age at birth $>34$ years and birth interval $<24$ months

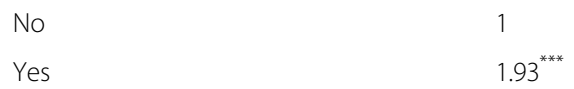

$(1.83,2.05)$

Age at birth $>34$ years and birth order $>3$

$\begin{array}{ll}\text { No } & 1 \\ \text { Yes } & 0.98\end{array}$

$(0.95,1.01)$

Age at birth $>34$ years and birth interval $<24$ months and birth order $>3$

No 1

Yes $1.95^{* * *}$

$(1.84,2.06)$

Birth interval $<24$ months and birth order $>3$

No 1

Yes $1.82^{* * *}$

$(1.76,1.88)$

Country fixed effects $\quad$ Yes

Time-fixed effects Yes

Exponentiated coefficients; 95\% confidence intervals in brackets

${ }^{*} P<0.05,{ }^{* *} P<0.01,{ }^{* * *} P<0.001$

live births) to a highest in Niger (125 per 1.000 live births). Average underfive mortality rates decreased from approximately 93 per 1000 live births during 1986-2000 to 77 during 2001-2010 and 52 during 2011-2017.

Mother's age $<18$ years at birth of the index child and PBI $<24$ months were significant risk factors of underfive mortality, while birth order $>3$ was protective.

Our major finding of mother's age $<18$ years being a risk factor of underfive mortality is consistent with many previous studies linking young mothers with high underfive mortality [30-34]. Underfives born to young 


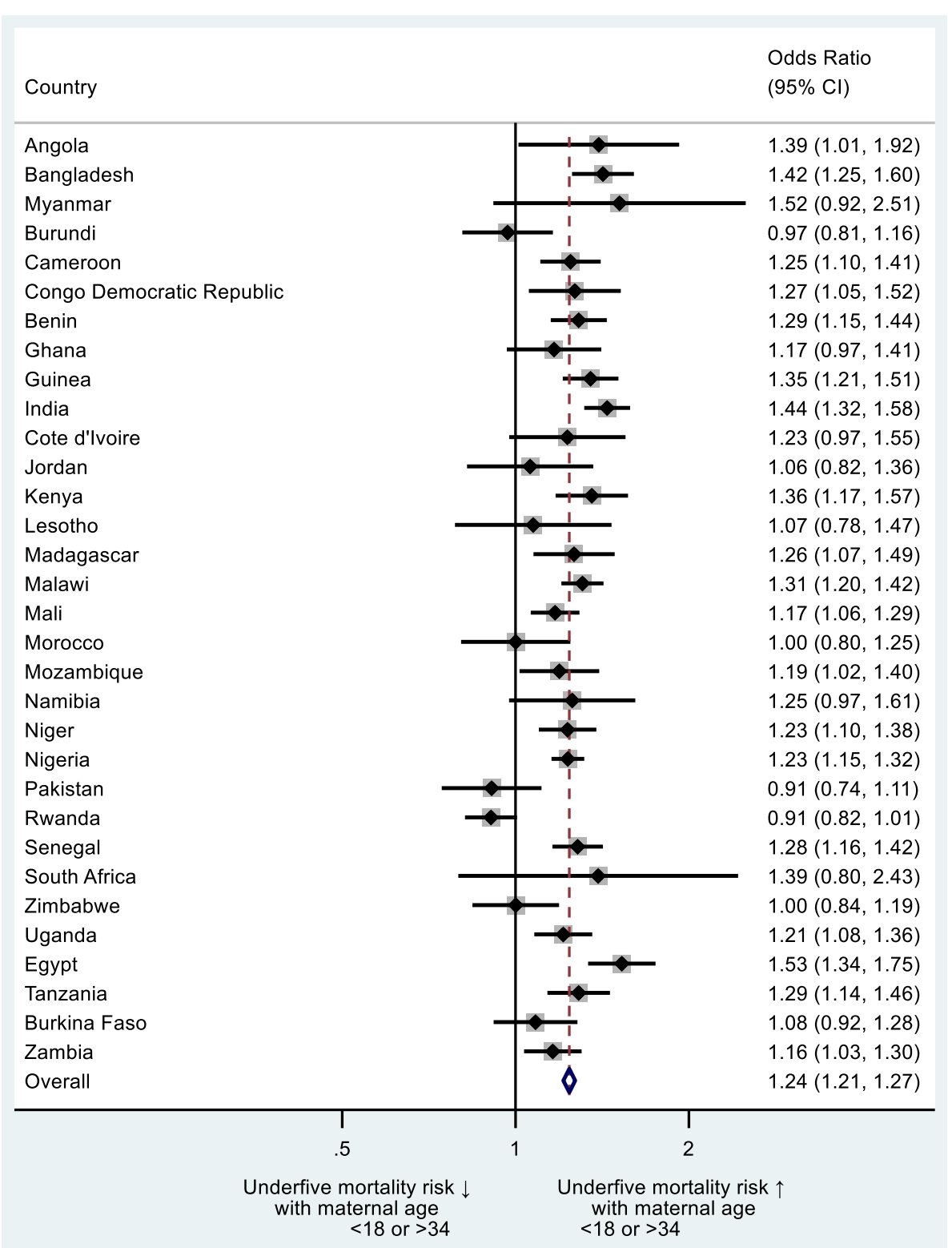

Fig. 2 Country-level odds ratios: mother's age at birth of index child $<18$ or $>34$ years as risk factor of underfive mortality

mothers are vulnerable to malnutrition and morbidity, leading to higher risks of mortality than those born to adult mothers. Young mothers are not fully matured physically and deprived of nutritional and biological advantages, which directly affect foetal development [35]. Young mothers have higher risks of adverse birth outcomes, such as low birth weight, stunting and infant mortality [36-38]. Young mothers are less experienced in child care than older ones and their children may be more vulnerable to unintentional injuries. Such injuries, the third leading cause of underfive mortality in the world, include drowning, traffic accidents, accidental asphyxia, poisoning and falls [39]. In the US maternal age between 15 to 24 years was associated with a significantly higher risk of sudden unexpected infant death than maternal age $>30$ years [40]. In a study in Pakistan children born to mothers who were married as minors were significantly more likely to suffer from repeated episodes of diarrhoea than those born to women married as adults and diarrhoea has been found to be one of the leading causes of underfive mortality [41].

Women married at younger ages have little decisionmaking power with respect to their health and that of their children in LMIC [42]. Child brides have smaller bargaining power within households compared with their adult counterparts [43]. As women are not allowed to visit a doctor without a male family member in some contexts [44], access to healthcare may be difficult when 


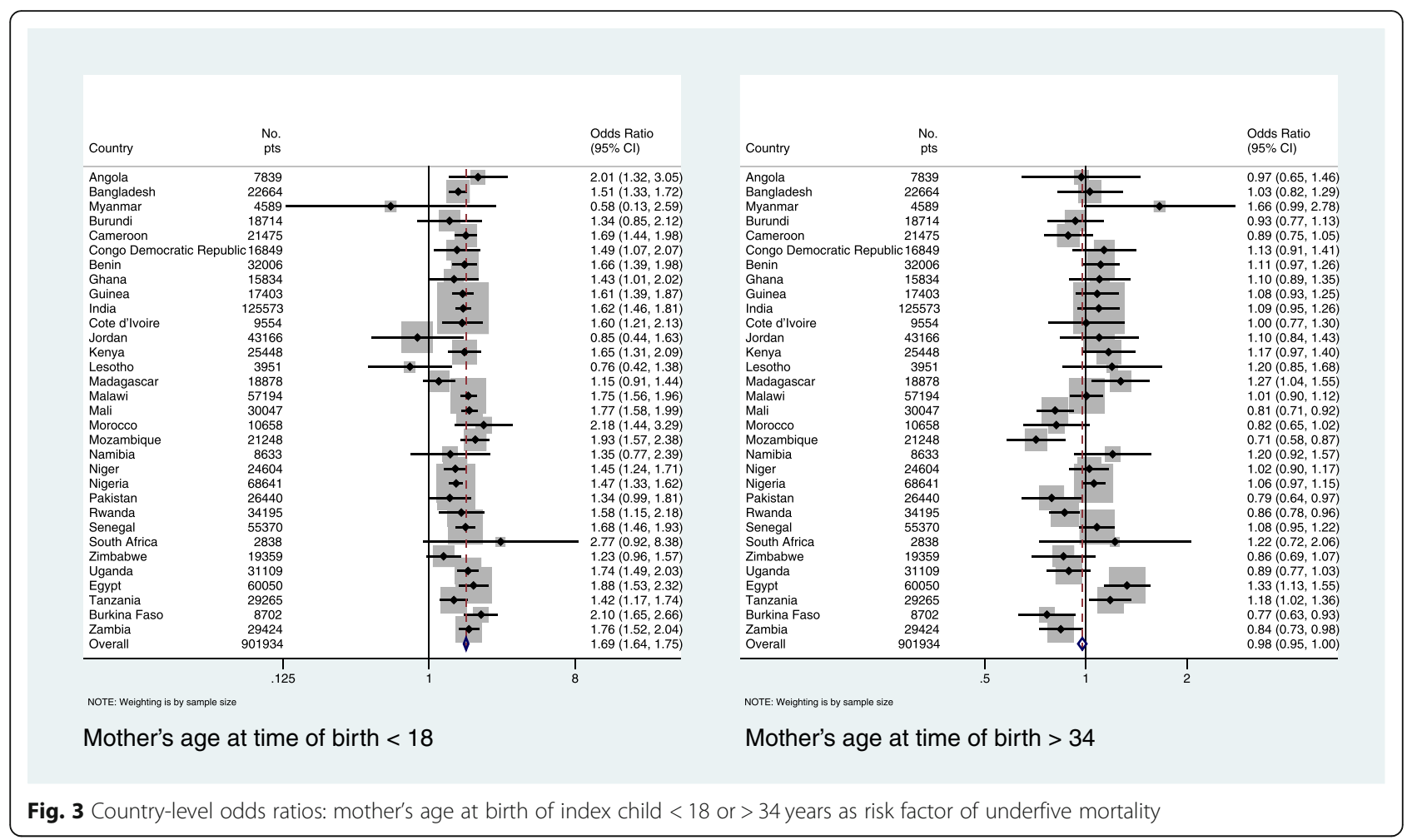

women married young [44]. In some resource-constrained settings, girl brides may themselves have limited access to adequate nutrition, which may, in turn, result in reduced foetal nutrition and breastfeeding $[45,46]$. Consequently, combined effects of foetal malnutrition and suboptimal breastfeeding may increase underfive mortality.

PBI $<24$ months appeared to be the strongest predictor of underfive mortality in our study, in accordance with many previous studies [7, 31, 47-50]. Different mechanisms have been proposed to explain this. The maternal depletion hypothesis suggests that with short PBIs women cannot recover their nutritional stores which may result in malnutrition in the next pregnancy [51]. Malnutrition may result in depletion of folate stores and folate insufficiency is associated with increased risks of anaemia, stunted intrauterine growth, preterm birth and neural tube defects [52-54]. Faced with malnutrition, women's bodies are known to prioritise their own needs over the nutritional needs of the foetus [55].

The sibling rivalry hypothesis is another theoretical explanation that short PBIs are associated with the risk of underfive mortality. This sibling hypothesis suggests that closely spaced children compete for attention of the parents as well as for scarce resources in the household, resulting in a weakened immune system, increased risks of infectious diseases and mortality among children [56]. Low birthweight, stunted growth of the neonate as well as decreased quality and quantity of breastmilk may mediate between PBI and underfive mortality [57].

Short PBIs are associated with increased risks of premature rupture of membranes, antepartum haemorrhage, anaemia, placental abruption, which ultimately may increase the risk of stillbirth and neonatal mortality $[53,58]$. Depression of the mother may also increase the risk of subsequent mortality of infants [59].

Evidence suggests that older siblings have a crucial role as caretakers of younger ones [60]. A study in Australia found that supervision lapses, which were partly due to indoor and outdoor household duties and talking/ socialising. Lack of supervision was the major reason behind fatal unintentional drownings of children [61].

Birth order $>3$ was protective against underfive mortality in our study. This finding contradicts the dominant view that higher birth order increases the risk of underfive mortality [48, 62-65]. Evidence also suggests an inverse- $U$ shaped relationship between birth order and underfive mortality, with second-born and third-borns having the highest risks [9].

Though lower age of the mother in high parity births could be a risk factor of underfive mortality, it is plausible to think that mothers learn from the experience of bringing up older children helping them take care of higher birth order children more effectively [66]. Parenting difficulties of first-born children such as sleep deprivation are also well documented [67]. Experienced 


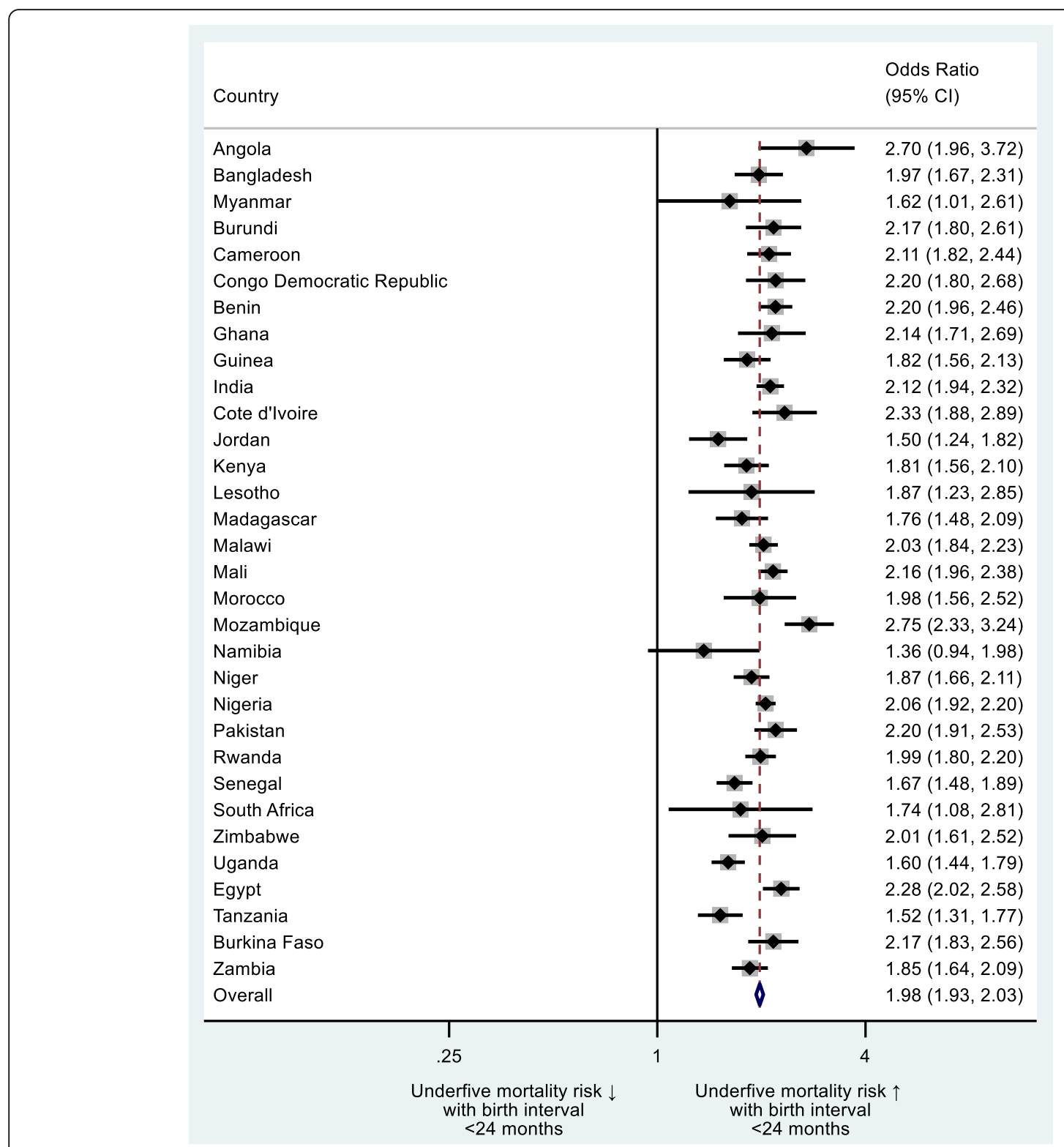

Fig. 4 Country-level odds ratios: preceding birth interval $(\mathrm{PBI})<24$ months as risk factor of underfive mortality

parents may cope more effectively with parental stress than first-timers [68].

Women in LMIC are often married young and the majority of them stay-at-home. Most of them are relatively young even after giving birth to a fourth and fifth child. This hypothesis is corroborated by our data: mean age of women giving birth to five children in our sample is 32 years. Also maternal age $>34$ years was not associated with significantly increased risks of underfive mortality. The relatively young maternal age, even when having high parity, may explain the protective effect of higherorder births against underfive mortality.

Higher mortality among children of higher birth order may also be explained by less access to healthcare than first or second-born children [69]. Health services in most LMIC, however, have been expanding over the time, making access to healthcare for children of higher birth order easier, leading to lower odds of underfive mortality for high parity births [70].

Some studies, in contrast with our findings, showed older maternal age as risk factor of underfive mortality $[71,72]$. In our study very few women gave birth at age > 34 years (14\%) and even less than 3\% after 40 [45]. Some specific combinations of HRFB such as maternal age $<18$ years and PBI $<24$ months significantly increased the odds of underfive mortality.

This study has some limitations. Different geographic regimes have different social, cultural and economic 


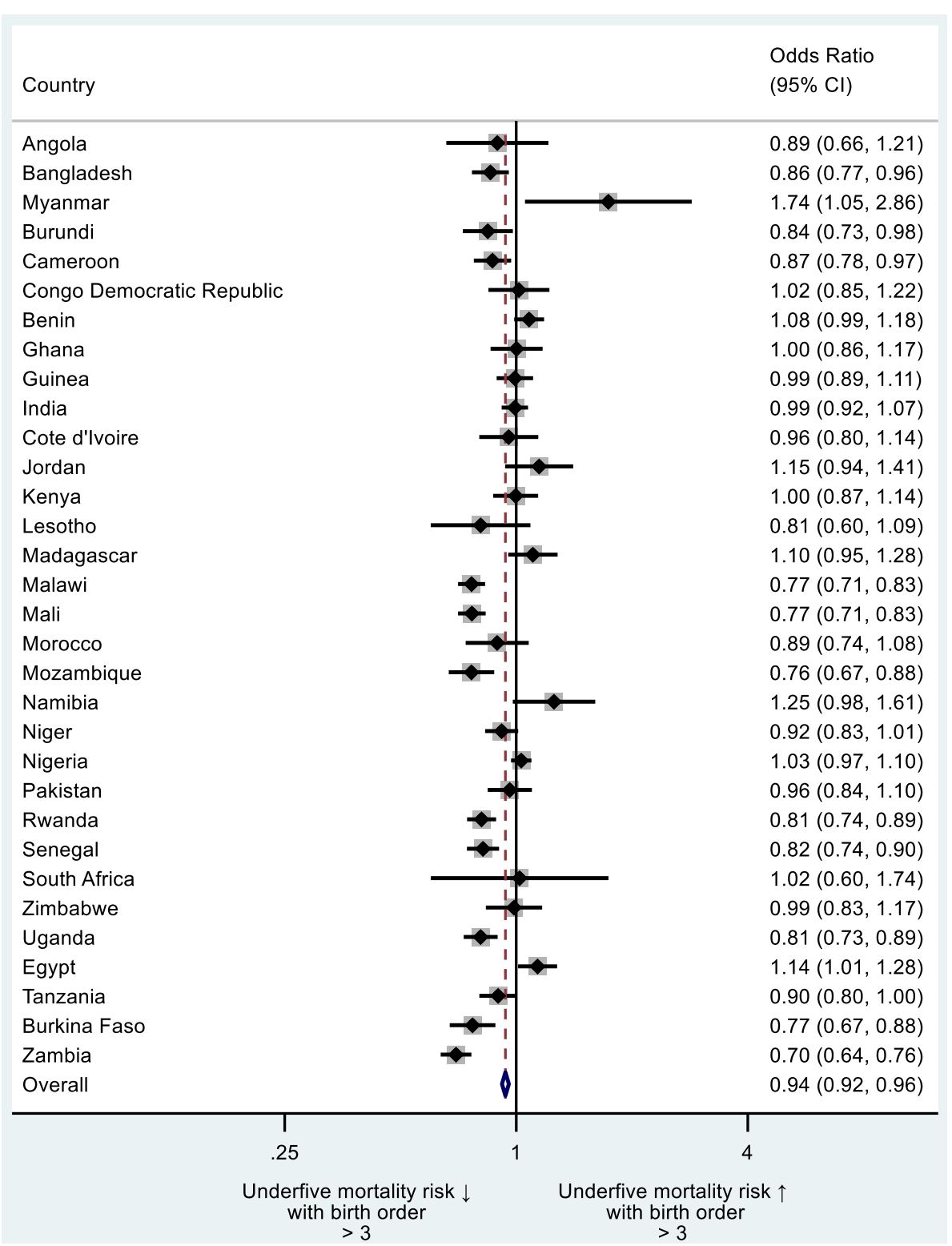

Fig. 5 Country-level odds ratios: child's birth order $>3$ as risk factor of underfive mortality

dynamics. Various health vulnerabilities and country- and region-specific characteristics of the participants could be a potential source of bias. As exposure variables were based on interviews and self-reported accounts occurring in the previous 5 years, a likelihood of recall bias may have been present. Further, causality between risk factors and underfive mortality cannot be assessed because the data utilized in our study is of cross-sectional in nature.

\section{Conclusions}

This study analysed associations between HRFB and underfive mortality using DHS data from 32 countries. Younger maternal age and short PBI significantly increased the risks of underfive mortality. In contrast, higher birth order was associated with lower risk. Maternal age $>34$ years did not turn out to be a risk factor. HRFB analysis also showed that presence of any single factor of HRFB as well as combinations of factors of HRFB significantly increased the risk of underfive mortality. These findings highlight the need for effective legislation to curb teenage marriages and increased public investment in reproductive healthcare with a focus on contraceptive use for an optimal birth spacing.

\section{Abbreviations}

aOR: adjusted Odds Ratio; Cl: Confidence Interval; HRFBs: High-risk fertility behaviours; DHS: Demographic and Health Survey; LMICs: Low- and middleincome countries; PBI: Preceding birth interval; SDGs: Sustainable

Development Goals; UNIGME: United Nations Inter-Agency Group for Child 
Mortality Estimation; USAID: United States Agency for International Development

\section{Supplementary Information}

The online version contains supplementary material available at https://doi. org/10.1186/s12884-021-03780-y.

Additional file 1. High-risk fertility behaviours: no HRFB versus single versus multiple risk factors

\section{Acknowledgements}

We would like to acknowledge IPUMS-DHS for granting access to datasets for this study.

\section{Authors' contributions}

RAD and $A R$ have conceived the research idea of this paper. RAD and $L N$ have analysed the data and estimated the model. AR, UG, and MU have written the introduction, discussion, and results. RAD and $L N$ have written methods. UG, RAD, LN have critically evaluated the paper. All authors have agreed on the final version of the manuscript.

\section{Funding}

None.

\section{Availability of data and materials}

The datasets generated and analysed during the current study are available subject to permission from the DHS program, in the (IPUMS-DHS) repository (https://www.idhsdata.org/idhs/index.shtml).

\section{Declarations}

\section{Ethics approval and consent to participate}

Permission to use the data from all included countries was granted by the Measure DHS (https://dhsprogram.com/). We acquired permission to use the data from the DHS program. Personal identifier of study subject was anonymized by the DHS program. No further administrative permissions and/or licenses were acquired to access the data.

\section{Consent for publication}

Not applicable.

\section{Competing interests}

The authors declare no competing interest regarding the publication of this paper.

\section{Author details}

${ }^{1}$ Department of Economics, COMSATS University Islamabad, Lahore Campus, Lahore, Pakistan. ${ }^{2}$ Department of Economics, Karachi University, Karachi, Pakistan. ${ }^{3}$ Research Scholar, Department of Economics, COMSATS University Islamabad, Lahore, Pakistan. ${ }^{4}$ Department of Management Sciences, COMSATS University, Islamabad, Lahore Campus, Lahore, Pakistan. ${ }^{5}$ New ERA, Kalopul, Rudramati Marga, Kathmandu 44600, Bagmati, Nepal.

Received: 14 May 2020 Accepted: 7 April 2021

Published online: 01 May 2021

\section{References}

1. Under-five mortality. https://www.who.int/gho/child health/mortality/morta lity_under_five_text/en/. Accessed 12 Sept 2020.

2. World Health Organization (WHO). Levels \& Trends in Child Mortality: Sustainable development goals. https://childmortality.org/data. Accessed 12 Sept 2020.

3. World Health Organization (WHO). United Nations sustainable development summit: Sustainable development goals. http://www.who.int/topics/sustaina ble-development-goals/targets/en/. Accessed 12 Sept 2020

4. Corman $\mathrm{H}$, Grossman M. Determinants of neonatal mortality rates in the US: a reduced form model. J Health Econ. 1985;4(3):213-36. https://doi.org/10.1 016/0167-6296(85)90030-X.
5. Erdoğan E, Ener M, Arıca F. The strategic role of infant mortality in the process of economic growth: an application for high income OECD countries. Procedia Soc Behav Sci. 2013;99:19-25. https://doi.org/10.1016/j. sbspro.2013.10.467.

6. Amiri A, Gerdtham U-G. Impact of maternal and child health on economic growth: new evidence based granger causality and DEA analysis. In: Newborn and Child Health, Study Commissioned by the Partnership for Maternal, Lund University, Sweden; 2013.

7. Habimana-Kabano I, Broekhuis A, Hooimeijer P. The effect of pregnancy spacing on fetal survival and neonatal mortality in Rwanda: a Heckman selection analysis. J Biosoc Sci. 2016;48(3):358-73. https://doi.org/10.1017/ S0021932015000231

8. Santhya KG, Ram U, Acharya R, Jejeebhoy SJ, Ram F, Singh A. Associations between early marriage and young women's marital and reproductive health outcomes: evidence from India. Int Perspect Sex Reprod Health. 2010;36(03):132-9. https://doi.org/10.1363/3613210.

9. Uddin M. Child mortality in a developing country: a statistical analysis. J Appl Quant Method. 2009;4(3):270-83.

10. Rahman M, Haque SE, Zahan S, Islam J, Rahman M, Asaduzzaman MD, et al. Maternal high-risk fertility behavior and association with chronic undernutrition among children under age 5 y in India, Bangladesh, and Nepal: do poor children have a higher risk? Nutrition. 2018;49:32-40. https:// doi.org/10.1016/j.nut.2017.10.001.

11. Rahman M, Islam MJ, Haque SE, Saw YM, Haque MN, Duc NHC, et al. Association between high-risk fertility behaviours and the likelihood of chronic undernutrition and anaemia among married Bangladeshi women of reproductive age. Public Health Nutr. 2017;20(2):305-14. https://doi.org/10.1 017/S136898001600224X.

12. Finlay JE, Norton MK. Adolescent fertility and child health: the interaction of maternal age, parity and birth intervals in determining child health outcomes. Int J Child Health Nutr. 2017;6(1):16-33. https://doi.org/10.6000/1929-4247.2017.06.01.2.

13. Gurmu E, Tariku D. Correlates of High Risk Fertility Behaviour in Ethiopia: A Multilevel Analysis of the 2011 Ethiopian demographic and health survey data. J Health Med Nurs. 2017:39:86-95.

14. Mekonnen Y, Ayalew T, Dejene A. High-risk birth, fertility intention, and unmet need in Addis Ababa. Ethiop J Health Dev. 2017;12(2):1-8.

15. Loaiza E, Wong S. Marrying too young: end child marriage. New York: United Nations Population Fund; 2012

16. IIPS: International Institute for Population Sciences and Macro International. National Family Health Survey (NFHS-3), 2005-06: India. Mumbai: IIPS; 2007.

17. World Bank. Fertility rate, total (births per woman) - Sub-Saharan Africa, South Asia, East Asia \& Pacific (excluding high income), Latin America \& Caribbean. In: World Dev Ind. Washington: World Bank Group; 2020.

18. World Bank. Population growth (annual \%). In: World Dev Ind. Washington: World Bank Group; 2020.

19. Heger Boyle E, King M, Sobek M. IPUMS-demographic and health surveys: version 8 [dataset]. Minneapolis: IPUMS and ICF; 2020.

20. Afshan K, Narjis G, Qureshi IZ, Cappello M. Social determinants and causes of child mortality in Pakistan: analysis of national demographic health surveys from 1990 to 2013. J Paediatr Child Health. 2020;56(3):457-72. https://doi.org/10.1111/jpc.14670.

21. lqbal N, Gkiouleka A, Milner A, Montag D, Gallo V. Girls' hidden penalty: analysis of gender inequality in child mortality with data from 195 countries. BMJ Glob Health. 2018;3(5):e001028. https://doi.org/10.1136/bmjgh-2018-001028.

22. Fenta SM, Fenta HM. Risk factors of child mortality in Ethiopia: application of multilevel two-part model. PLoS One. 2020;15(8):e0237640. https://doi.org/1 0.1371/journal.pone.0237640.

23. Sankar MJ, Sinha B, Chowdhury R, Bhandari N, Taneja S, Martines J, et al. Optimal breastfeeding practices and infant and child mortality: a systematic review and meta-analysis. Acta Paediatr. 2015;104(467):3-13. https://doi. org/10.1111/apa.13147.

24. Samari G. First birth and the trajectory of women's empowerment in Egypt. BMC Pregnancy Childbirth. 2017;17(Suppl 2):362. https://doi.org/10.1186/s12 884-017-1494-2.

25. Yildizhan R, Adali E, Kolusari A, Kurdoglu M, Yildizhan B, Sahin G. Domestic violence against infertile women in a Turkish setting. Int J Gynaecol Obstet. 2009;104(2):110-2. https://doi.org/10.1016/j.ijgo.2 008.10.007

26. Anyamele OD, Ukawuilulu JO, Akanegbu BN. The role of wealth and mother's education in infant and child mortality in 26 sub-Saharan African countries: evidence from pooled demographic and health 
survey (DHS) data 2003-2011 and African development indicators (ADI), 2012. Soc Indic Res. 2017;130(3):1125-46. https://doi.org/10.1007/s11205015-1225-x.

27. Murray S, Mackay D, Stock S, Pell J, Norman J. Association of Gestational age at birth with risk of perinatal mortality and special educational need among twins. JAMA Pediatr. 2020;174(5):437-45. https://doi.org/10.1001/ja mapediatrics.2019.6317.

28. Bucher-Koenen T, Farbmacher H, Guber R, Vikstrom J. Double trouble: the burden of child-rearing and working on maternal mortality. Demography. 2020;57(2):559-76. https://doi.org/10.1007/s13524-020-00868-6.

29. World Health Organization. Estimation method for child mortality Used in: Level and Trends of Child mortality. Geneva: WHO, UNICEF, UN Population Division and World Bank; 2013.

30. Alam N. Teenage motherhood and infant mortality in Bangladesh: maternal age-dependent effect of parity one. J Biosoc Sci. 2000;32(2):229-36. https:// doi.org/10.1017/S0021932000002297.

31. Raj A, McDougal L, Rusch ML. Effects of young maternal age and short interpregnancy interval on infant mortality in South Asia. Int J Gynaecol Obstet. 2014;124(1):86-7. https://doi.org/10.1016/j.jigo.2013.07.027.

32. Perin J, Walker N. Potential confounding in the association between short birth intervals and increased neonatal, infant, and child mortality. Glob Health Action. 2015;8(1):29724. https://doi.org/10.3402/gha.v8.29724.

33. Wilson N. Child mortality risk and fertility: evidence from prevention of mother-to-child transmission of HIV. J Dev Econ. 2015;116:74-88. https://doi. org/10.1016/j.jdeveco.2015.01.007.

34. Kravdal O. New evidence about effects of reproductive variables on child mortality in sub-Saharan Africa. Popul Stud (Camb). 2018;72(2):139-56. https://doi.org/10.1080/00324728.2018.1439180.

35. de Vienne CM, Creveuil C, Dreyfus M. Does young maternal age increase the risk of adverse obstetric, fetal and neonatal outcomes: a cohort study. Eur J Obstet Gynecol Reprod Biol. 2009;147(2):151-6. https://doi.org/10.101 6/j.jogrb.2009.08.006.

36. Ganchimeg T, Ota E, Morisaki N, Laopaiboon M, Lumbiganon P, Zhang J, et al. Pregnancy and childbirth outcomes among adolescent mothers: $a$ World Health Organization multicountry study. BJOG. 2014;121:40-8. https:// doi.org/10.1111/1471-0528.12630.

37. Alio AP, Mbah AK, Grunsten RA, Salihu HM. Teenage pregnancy and the influence of paternal involvement on fetal outcomes. J Pediatr Adolesc Gynecol. 2011;24(6):404-9. https://doi.org/10.1016/j.jpag.2011.07.002.

38. Chen X-K, Wen SW, Fleming N, Demissie K, Rhoads GG, Walker M. Teenage pregnancy and adverse birth outcomes: a large population based retrospective cohort study. Int J Epidemiol. 2007;36(2):368-73. https://doi. org/10.1093/ije/dyl284.

39. Yao M, Wu G, Zhao Z, Luo M, Zhang J. Unintentional injury mortality among children under age five in urban and rural areas in the Sichuan province of West China, 2009-2017. Sci Rep. 2019;9(1):1-8.

40. Ferres JML, Anderson TM, Johnston R, Ramirez J-M, Mitchell EA. Distinct populations of sudden unexpected infant death based on age. Pediatrics. 2020;145(1):e20191637.

41. Walker CLF, Aryee MJ, Boschi-Pinto C, Black RE. Estimating diarrhea mortality among young children in low and middle income countries. PLoS One. 2012;7(1):e29151. https://doi.org/10.1371/journal.pone.0029151.

42. Raj A. When the mother is a child: the impact of child marriage on the health and human rights of girls. Arch Dis Child. 2010;95(11):931-935.

43. Parsons J, Edmeades J, Kes A, Petroni S, Sexton M, Wodon Q. Economic impacts of child marriage: a review of the literature. Rev Faith Int Aff. 2015; 13(3):12-22. https://doi.org/10.1080/15570274.2015.1075757.

44. Nasrullah M, Muazzam S, Bhutta ZA, Raj A. Girl child marriage and its effect on fertility in Pakistan: findings from Pakistan demographic and health survey, 2006-2007. Matern Child Health J. 2014;18(3):534-43. https://doi. org/10.1007/s10995-013-1269-y.

45. Morris JM, Totterdell J, Bin YS, Ford JB, Roberts CL. Contribution of maternal age, medical and obstetric history to maternal and perinatal morbidity/ mortality for women aged 35 or older. Aust N Z J Obstet Gynaecol. 2018; 58(1):91-7. https://doi.org/10.1111/ajo.12674.

46. Raj A, Saggurti N, Winter M, Labonte A, Decker MR, Balaiah D, et al. The effect of maternal child marriage on morbidity and mortality of children under 5 in India: cross sectional study of a nationally representative sample. BMJ. 2010;340(jan21 1):b4258. https://doi.org/10.1136/bmj.b4258.

47. Ezeh OK, Agho KE, Dibley MJ, Hall J, Page AN. Determinants of neonatal mortality in Nigeria: evidence from the 2008 demographic and health survey. BMC Public Health. 2014;14(1):521. https://doi.org/10.1186/1471-24 58-14-521.

48. Brown W, Ahmed S, Roche N, Sonneveldt E, Darmstadt GL. Impact of family planning programs in reducing high-risk births due to younger and older maternal age, short birth intervals, and high parity. Semin Perinatol. 2015; 39(5):338-44. https://doi.org/10.1053/j.semperi.2015.06.006.

49. Hossain MM, Mani KK, Islam MR. Prevalence and determinants of the gender differentials risk factors of child deaths in Bangladesh: evidence from the Bangladesh demographic and health survey, 2011. PLoS Negl Trop Dis. 2015;9(3):e0003616. https://doi.org/10.1371/journal.pntd.0003616.

50. Ezeh OK. Trends and population-attributable risk estimates for predictors of early neonatal mortality in Nigeria, 2003-2013: a cross-sectional analysis. BMJ Open. 2017;7(5):e013350. https://doi.org/10.1136/bmjopen-2016-013350.

51. Molitoris J. The effect of birth spacing on child mortality in Sweden, 18781926. Popul Dev Rev. 2017:43(1):61-82.

52. Zhu BP. Effect of interpregnancy interval on birth outcomes: findings from three recent US studies. Int J Gynaecol Obstet. 2005;89:S25-33. https://doi. org/10.1016/j.jijgo.2004.08.002.

53. Conde-Agudelo A, Rosas-Bermúdez A, Kafury-Goeta AC. Effects of birth spacing on maternal health: a systematic review. Am J Obstet Gynecol. 2007:196(4):297-308. https://doi.org/10.1016/j.ajog.2006.05.055.

54. Conde-Agudelo A, Rosas-Bermudez A, Castaño F, Norton MH. Effects of birth spacing on maternal, perinatal, infant, and child health: a systematic review of causal mechanisms. Stud Fam Plan. 2012;43(2):93-114. https://doi. org/10.1111/j.1728-4465.2012.00308.x.

55. Ellison PT. Energetics and reproductive effort. Am J Hum Biol. 2003;15(3): 342-51. https://doi.org/10.1002/ajhb.10152.

56. Tariku L. Effects of preceding birth intervals on child mortality in Ethiopia; Evidence from the Demographic and Health Surveys, 2016. Epidemology Int J. 2019:3(1):1-7.

57. Marquis GS, Penny ME, Zimmer JP, Díaz JM, Marín RM. An overlap of breastfeeding during late pregnancy is associated with subsequent changes in colostrum composition and morbidity rates among Peruvian infants and their mothers. J Nutr. 2003;133(8):2585-91. https://doi.org/10.1093/jn/133.8.2585.

58. Conde-Agudelo A, Belizán JM. Maternal morbidity and mortality associated with interpregnancy interval: cross sectional study. BMJ. 2000;321(7271): 1255-9. https://doi.org/10.1136/bmj.321.7271.1255.

59. Stephansson O, Dickman PW, Cnattingius S. The influence of interpregnancy interval on the subsequent risk of stillbirth and early neonatal death. Obstet Gynecol. 2003;102(1):101-8. https://doi.org/10.1016/s0029-7844(03)00366-1.

60. Wikle JS, Jensen AC, Hoagland AM. Adolescent caretaking of younger siblings. Soc Sci Res. 2018;71:72-84. https://doi.org/10.1016/j.ssresearch.201 7.12.007.

61. Peden AE, Franklin RC. Causes of distraction leading to supervision lapses in cases of fatal drowning of children 0-4 years in Australia: a 15-year review. $J$ Paediatr Child Health. 2020;56(3):450-6. https://doi.org/10.1111/jpc.14668.

62. Conde-Agudelo A, Rosas-Bermúdez A, Kafury-Goeta AC. Birth spacing and risk of adverse perinatal outcomes: a meta-analysis. JAMA. 2006;295(15): 1809-23. https://doi.org/10.1001/jama.295.15.1809.

63. DaVanzo J, Hale L, Razzaque A, Rahman M. The effects of pregnancy spacing on infant and child mortality in Matlab, Bangladesh: how they vary by the type of pregnancy outcome that began the interval. Popul Stud. 2008:62(2):131-54. https://doi.org/10.1080/00324720802022089.

64. Akinyemi JO, Bamgboye EA, Ayeni O. New trends in under-five mortality determinants and their effects on child survival in Nigeria: A review of childhood mortality data from 1990-2008. Afr Popul Stud. 2013;27(1):25-42.

65. Fotso JC, Cleland J, Mberu B, Mutua M, Elungata P. Birth spacing and child mortality: an analysis of prospective data from the Nairobi urban health and demographic surveillance system. J Biosoc Sci. 2013;45(6):779-98. https:// doi.org/10.1017/S0021932012000570

66. Handa S, Koch S, Ng SW. Child mortality in eastern and southern Africa. Popul Rev. 2010:49(1):8-35.

67. Fuse K. Gender and parenting difficulty of the first-born: implications for parity progression among Japanese couples. J Comp Fam Stud. 2019;50(2): 116-38. https://doi.org/10.3138/jcfs.50.2.002.

68. Richter D, Krämer MD, Tang NK, Montgomery-Downs HE, Lemola S. Long-term effects of pregnancy and childbirth on sleep satisfaction and duration of first-time and experienced mothers and fathers. Sleep. 2019: 42(4):Zsz015.

69. Sonneveldt E, Plosky WD, Stover J. Linking high parity and maternal and child mortality: what is the impact of lower health services coverage among 
higher order births? BMC Public Health. 2013;13(S3):S7. https://doi.org/10.11 86/1471-2458-13-S3-S7.

70. Albutt K, Sonderman K, Citron I, Nthele M, Bekele A, Makasa E, et al. Healthcare leaders develop strategies for expanding national surgical, obstetric, and anaesthesia plans in WHO AFRO and EMRO regions. World J Surg. 2019:43(2):360-7. https://doi.org/10.1007/s00268-018-4819-z.

71. Weerasekera D, Udugama SG. Pregnancy at 40 and over: a case-control study in a developing country. J Obstet Gynaecol. 2003;23(6):625-7. https:// doi.org/10.1080/01443610310001604385.

72. Yogev Y, Melamed N, Bardin R, et al. Pregnancy outcome at extremely advanced maternal age. Am J Obstet Gynecol. 2010;203(6):558.e551-7.

\section{Publisher's Note}

Springer Nature remains neutral with regard to jurisdictional claims in published maps and institutional affiliations.

Ready to submit your research? Choose BMC and benefit from:

- fast, convenient online submission

- thorough peer review by experienced researchers in your field

- rapid publication on acceptance

- support for research data, including large and complex data types

- gold Open Access which fosters wider collaboration and increased citations

- maximum visibility for your research: over $100 \mathrm{M}$ website views per year

At BMC, research is always in progress.

Learn more biomedcentral.com/submissions 